\title{
Study of Hand Arm Vibration in VNMKV Developed Power Weeder
}

\author{
P. A. Munde, A. D. Harkal* and G. S. Bhumare \\ Department of farm Machinery and power engineering, CAET, VNMKV, Parbhani, India \\ *Corresponding author
}

\begin{tabular}{|l|}
\hline Ke y w o r d s \\
Power weeder, \\
$\begin{array}{l}\text { Hand arm } \\
\text { Vibration, Rubber } \\
\text { interventions }\end{array}$ \\
\hline Article Info \\
\hline $\begin{array}{l}\text { Accepted: } \\
\text { 14 November } 2020 \\
\text { Available Online: } \\
10 \text { December } 2020\end{array}$ \\
\hline
\end{tabular}

\section{A B S T R A C T}

Weeding is an important but equally labour intensive agricultural unit operation. Nonchemical weeding is required for ensuring food safety. With mechanical weeding methods, it is possible to control weeds in a way that meets consumer and environmental demands. Mechanical vibrations have immediate and long term effects upon the human body. It depend upon the duration of exposure and the frequency of vibrations. For walk behind machines, vibrations are transmitted to the operator through his hands while in case riding type, vibrations are transmitted to the operator through seat as whole body vibrations (WBV) and through his hands as hand-arms vibrations (HAV). The power weeder was designed and developed in department of farm Machinery and power CAET, VNMKV, Parbhani. Hand arm vibration study was conducted with four rubber interventions I 1(A1B1), I2 (A1B2), I3(A2B1) I4 (A2 B2) A1 Synthetic rubber (Styrene-Butadiene Rubber); A2 Foam rubber (Nitrile rubber) B. Hand Grips soft handgrip of foam rubber ; $\mathrm{B} 2$ general hand grip\}, three speeds $(\mathrm{S} 1=1.2 \mathrm{kmph}, \mathrm{S} 2=1.5 \mathrm{kmph}, \mathrm{S} 3=1.8 \mathrm{kmph})$ and two type of Blade. Straight blade, and Rotary blade. It was observed that In weeding with straight blade, the vibration magnitude increased with speed. The vibration magnitude in $x$ direction was higher than $\mathrm{y}$ and $\mathrm{z}$ directions. The $\mathrm{x}$ axis acceleration exceeds $1 \mathrm{~h}, 1.5 \mathrm{~h}, 2 \mathrm{~h}$ exposure limit at $1.8,1.5 .1 .2 \mathrm{kmph}$. The peak value in $\mathrm{x}$ direction was found at $50 \mathrm{~Hz}$ and around $160 \mathrm{~Hz}$. it is observed that vibration levels were higher in x-direction. The vibration magnitudes were concentration over a frequency range of $0-20 \mathrm{~Hz}$. With intervention I1 i.e Synthetic rubber with soft foam rubber hand grip ,there was reduction of 34 percent and 30.5 percent in HTV at speed of $1.8 \mathrm{kmph}$ for straight and rotary blade respectively followed by $\mathrm{I} 2, \mathrm{I} 3$, and I4 has the lesser reduction in the HTV but it has less HTV values than the control i.e no intervention. Maximum time of exposure to vibrations was increased from one hour to two hours in case of rotary blade at all three speeds i.e. $1.2,1.5,1.8 \mathrm{kmph}$ and the period was increased from two to four hours in case of straight blade weeding operations.

\section{Introduction}

Weed management in field crops required an integrated approach that utilizes preventive measures as well as effective cultural, mechanical, biological and chemical control methods in a mutually supported manner with due consideration to economic, environmental and sociological consequences. Shivdas, (2003) stated the power weeders with rotary 
blades performed the work much better than the fixed blade type particularly at high moisture soil conditions. Mechanical vibrations have immediate and long term effects upon the human body. It depends upon the duration of exposure and the frequency of vibrations. For walk behind machines, vibrations are transmitted to the operator through his hands while in case riding type, vibrations are transmitted to the operator through seat as whole body vibrations (WBV) and through his hands as hand-arms vibrations (HAV). Palmer et.al (2001) found that Workers exposed to hand arm vibrations often experience aches and pains in upper limbs. Buckle, 1997 stated that forceful, repetitive manual work, along with prolonged static loading and exposure to vibrations are established areas of risk.

\section{Materials and Methods}

A Power weeder was developed in the department of farm Machinery and Power CAET, VNMKV Parbhani. The specifications of developed Power weeder were as fallows

Hand arm vibration study was conducted with four rubber interventions I 1 (A1B1), I2 (A1B2), I3(A2B1) I4 (A2 B2) A1 Synthetic rubber (Styrene-Butadiene Rubber); A2 Foam rubber (Nitrile rubber) Two Hand Grips B1 soft handgrip of foam rubber; B2 general hand grip \}, three speeds $(\mathrm{S} 1=1.2 \mathrm{kmph}$, $\mathrm{S} 2=1.5 \mathrm{kmph}, \mathrm{S} 3=1.8 \mathrm{kmph}$ ) and two type of Blade. Straight blade, and Rotary blade.

\section{Direction of vibration}

It is known that the vibration entering the hand contains contributions from all three measurement directions. Therefore, the measurement should preferably be made for all three directions simultaneously. Figure 1 illustrate an anatomical and basicentric coordinate system for measurement of hand transmitted vibration exposure as defined in ISO 5349-1(2001). The coordinate system will then define as: $\mathrm{z}$-axis is defined as the longitudinal axis of the third metacarpal bone and is oriented positively towards the distal end of the finger. The $\mathrm{x}$-axis passes through origin, is perpendicular to the z-axis and is positive in the forward direction when the hand is in normal anatomical position (palm facing forwards). The $y$-axis is perpendicular to the other two axes and positive in the direction towards the fifth finger (thumb). In practice the basicentric coordinate system is used. The system is generally rotated in the y$\mathrm{z}$ plane so that $\mathrm{y}$-axis is parallel to the handle axis.

\section{Magnitude of vibration}

When the human body is in contact with a vibrating mechanical device, it is displaced about its contact position (Sanders and Mccormick, 1993). Displacement is therefore one parameter which can be used to describe the magnitude of a vibration. Although displacement, velocity and acceleration can be used for quantifying the vibration severity. Human response to vibration is highly dependent on the frequency of the vibration. As per the ISO 5349(2001) recommendations, the most important quantity used to describe the magnitude of vibration transmitted to the operator's hands is root mean square (rms) frequency weighted acceleration in ms-2 expressed as

$$
a_{h w}=\left[\sum_{j=1}^{n}\left(W_{h} a_{h y}\right)^{2}\right]^{1 / 2}
$$

Where

$\mathrm{A}_{\mathrm{hw}}=$ Root mean square (rms) frequency weighted acceleration, $\mathrm{w}_{\mathrm{h}}=$ Weighting factor for jth one-third octave band, $a_{h j}=r m s$ acceleration measured in one-third octave band used in ms-2 
$\mathrm{n}=$ number of frequencies used in the octave band

The weighted value should be determined over the eight octave bands (i.e $\mathrm{n}=8$ ) from 8 to $1000 \mathrm{~Hz}$ or over the 24 one third octave bands (i.e $\mathrm{n}=24$ ) from 6.3 to $1250 \mathrm{~Hz}$. The one third octave band is very common and is adopted in the ISO 5349 (2001). The sensitivity of body to different frequencies is different, so weighting factor for different frequency bands are defined in ISO 5349-1 (2001) which are given in the table 1. It is clear from the table that the hand-transmitted vibration is more sensitive to the frequency range of 6.3 to $31.5 \mathrm{~Hz}$.

Vector sum of the frequency weighted acceleration (Vibration total values) in three axes represents the acute effects better than does the weighted acceleration in the main axis alone. This is the vibration total value ahv and it is defined as the rms of the three component values given below

$$
a_{k v}=\sqrt{\left(a_{k e x}\right)^{2}+\left(a_{k m p}\right)^{2}+\left(a_{k m z}\right)^{2}}
$$

Where, $a_{h v}=$ overall weightage vibration acceleration, $a_{h w x}=$ weighted vibration acceleration for $\mathrm{x}$-axis, $\mathrm{a}_{\mathrm{hwy}}=$ weighted vibration acceleration for $\mathrm{y}$-axis, $\mathrm{a}_{\mathrm{hwz}}=$ weighted vibration acceleration for $\mathrm{z}$-axis.

Therefore the vector sum of vibration intensity is virtually independent of the orientation of the coordinate system.

Hand arm vibration meter used is the SV 106 a new six-channel human vibration meter and analyser. Instrument meets requirements of ISO 8041:2005 standard and it is an ideal choice for measurements according to ISO 2631-1,2\&5 and ISO 5349. This revolutionary, pocket-size instrument enables simultaneous measurements with two triaxial accelerometers (e.g. both-hands vibration or tri axial SEAT transmission measurements are possible). The RMS, Peak, Peak-Peak, VDV, MTVV or dose results such as A(8) and Aeq with all required weighting filters for the HVM measurements, including band-limiting filters, are available with this instrument.

\section{Hand-arm vibrations (HTV) without interventions}

The Hand transmitted vibrations for all the tree axes as defined in ISO 5349(2010) was measured and recorded in different field operations. The hand transmitted vibration (rms acceleration $\mathrm{ms}^{-2}$ are shown in the graphs for weeding and rotary inter culturing operation for $\mathrm{x}, \mathrm{y}, \mathrm{z}$ directions in Fig. 2.

It is clear from graphs that HTV increased in all three directions with increase in speed in all two operating conditions. The maximum value vibration in $x$ direction $5.96 \mathrm{~m} / \mathrm{s}^{2}$ and 8 $\mathrm{m} / \mathrm{s}^{2}$ in straight blade weeder, and rotary weeder respectively. The magnitudes were higher in $\mathrm{X}$ - direction indicating that $\mathrm{x}$ direction was major contributor in total vibration value. In rotary weeder magnitudes of vibration reduced in $\mathrm{Y}$ and $\mathrm{Z}$ direction at $1.8 \mathrm{kmph}$. it might be due to the reduction of side movement of weeder and greater draft force on weeding assembly produced drag reduced vibration in horizontal direction due to the large amount of soil handled per unit time by tines of weeder also damped vibrations. The other reason could be higher amplitude vibration at frequencies with lower weighting factor might have resulted in lower vibration value. The vibration magnitudes in rotary weeder in $\mathrm{X}$ direction than with straight blade. The vibration magnitude in $\mathrm{Y}$ andz direction were higher for straight blade weeder as compared to rotary weeder. It may be due to movement in forward and transverse direction due to hitching arrangement. In case of rotary weeder attachment is rigid with 

transverse system, also links provided to direction for single axle tractor with rotary
handle. Lowest value of vibration was in $\mathrm{Y}$ cultivator.

Table.1 Effect of interventions on HTV

\begin{tabular}{|c|c|c|c|c|c|c|c|c|c|c|}
\hline \multirow[t]{3}{*}{ Operation } & \multirow{3}{*}{$\begin{array}{l}\text { Speed } \\
\text { kmph }\end{array}$} & \multicolumn{9}{|c|}{ Vibration total value $\mathrm{m} / \mathrm{s}^{2}$} \\
\hline & & \multirow[t]{2}{*}{$\begin{array}{l}\text { Without } \\
\text { intervention } \\
\text { (W) }\end{array}$} & \multicolumn{2}{|c|}{$\begin{array}{l}\text { Rubber + soft } \\
\text { grip } \\
\text { (I1) }\end{array}$} & \multicolumn{2}{|c|}{$\begin{array}{l}\text { Rubber + Hard } \\
\text { grip } \\
\text { (I2) }\end{array}$} & \multicolumn{2}{|c|}{$\begin{array}{l}\text { PU foam }+ \text { soft } \\
\text { grip } \\
\text { (I3) }\end{array}$} & \multicolumn{2}{|c|}{$\begin{array}{l}\text { Pu foam }+ \\
\text { Hard grip } \\
\text { (I4) }\end{array}$} \\
\hline & & & $\begin{array}{l}\text { Magnit } \\
\text { ude }\end{array}$ & $\begin{array}{c}\% \\
\text { red }\end{array}$ & $\begin{array}{l}\text { Magnitu } \\
\text { de }\end{array}$ & $\begin{array}{c}\% \\
\text { red }\end{array}$ & $\begin{array}{c}\text { Magnit } \\
\text { ude. }\end{array}$ & $\%$ red & $\begin{array}{c}\text { Magnit } \\
\text { ude }\end{array}$ & $\begin{array}{c}\% \\
\text { red }\end{array}$ \\
\hline \multirow{3}{*}{$\begin{array}{c}\text { Straight } \\
\text { blade }\end{array}$} & 1.2 & 6.57 & 4.51 & 31.4 & 4.93 & 25 & 5.06 & 23 & 5.19 & 21 \\
\hline & 1.5 & 7.14 & 4.80 & 32.8 & 5.48 & 23.2 & 5.53 & 22.5 & 5.61 & 21.4 \\
\hline & 1.8 & 6.37 & 4.20 & 34 & 4.97 & 21.9 & 4.92 & 22.8 & 5.05 & 20.7 \\
\hline \multirow{3}{*}{$\begin{array}{l}\text { Rotary } \\
\text { Blade }\end{array}$} & 1.2 & 6,58 & 4.67 & 29 & 5.13 & 22 & 5.14 & 21.8 & 5.24 & 20.4 \\
\hline & 1.5 & 7.21 & 4.97 & 31 & 5.64 & 21.7 & 5.66 & 21.5 & 5.77 & 20 \\
\hline & 1.8 & 8.43 & 5.86 & 30.5 & 6.58 & 21.9 & 6.68 & 20.8 & 6.77 & 19.7 \\
\hline
\end{tabular}

Fig.1 Coordinate system for hand

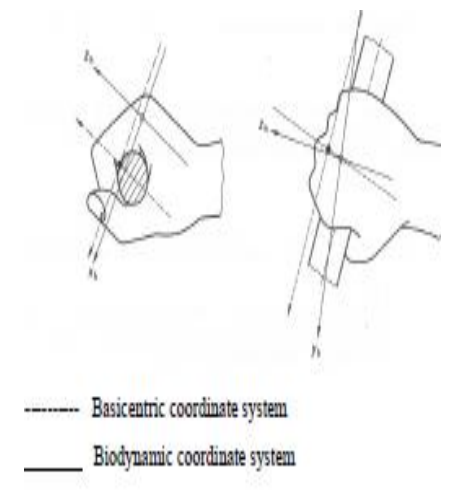

Fig.2 Vibration magnitude in Weeding operation (Straight blade and Rotary Blade)
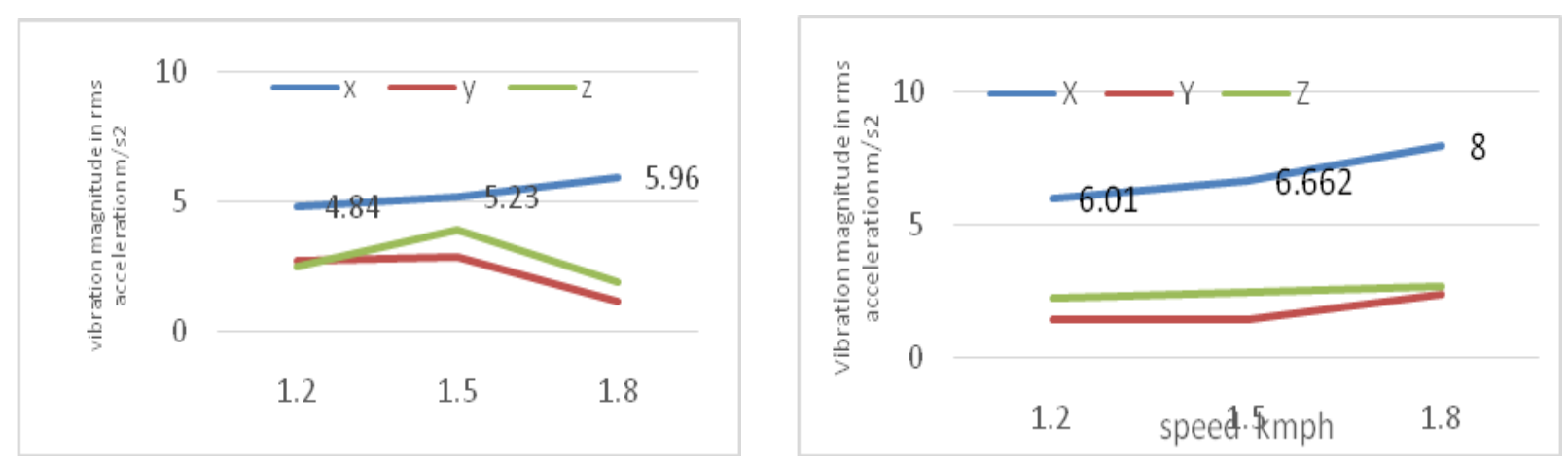
Fig.3
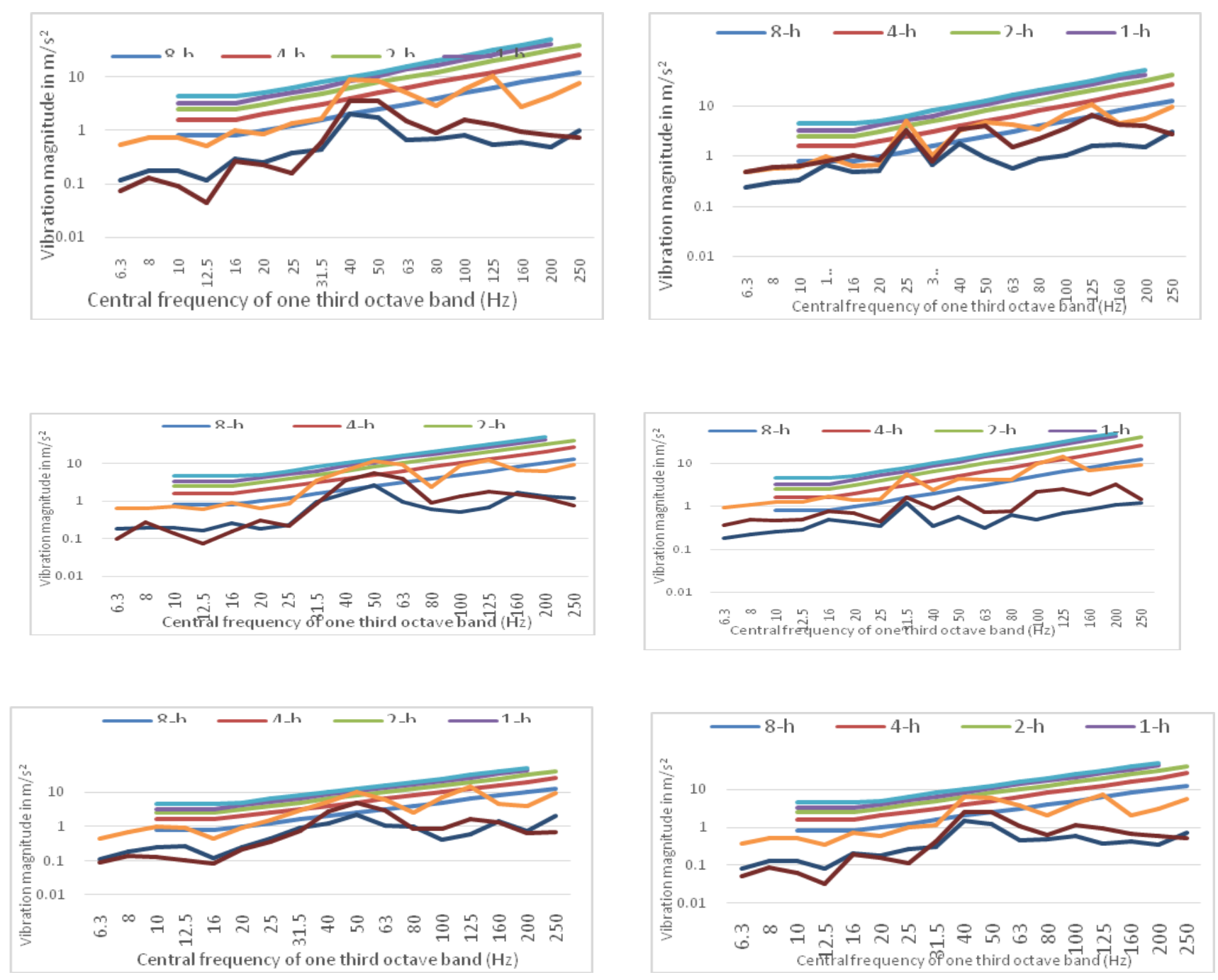

Frequency weighted vibrations for Rotary blade weeding at $1.2,1.5,1.8 \mathrm{kmph}$ without interventions

Frequency weighted vibrations for straight blade weeding at 1.2,1.5,1.8 kmph without interventions

Fig.4
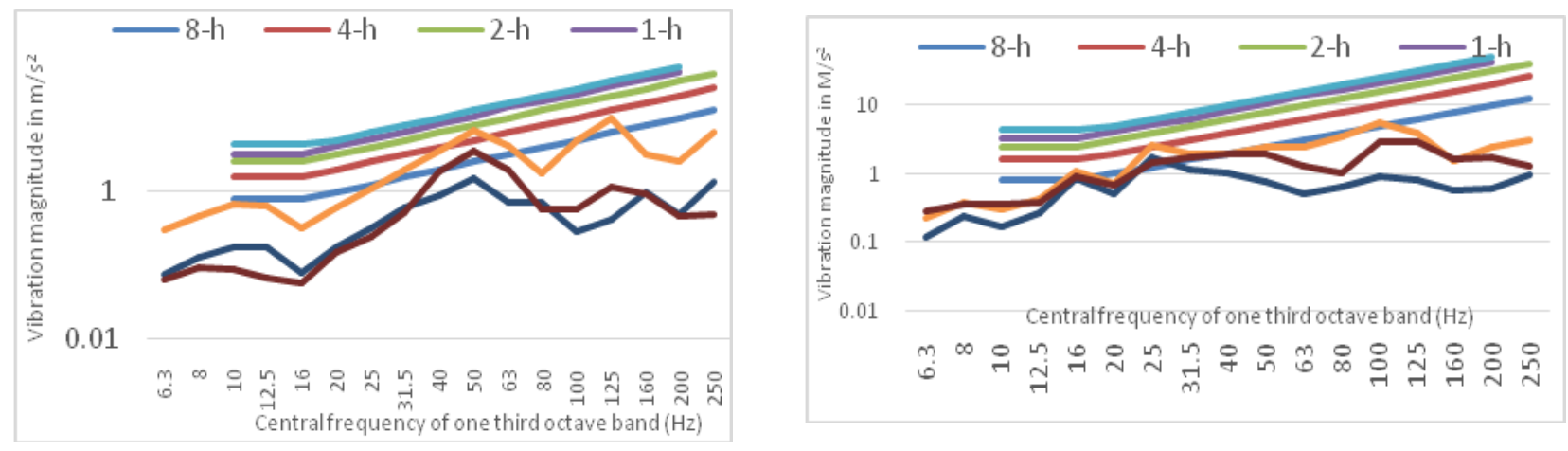

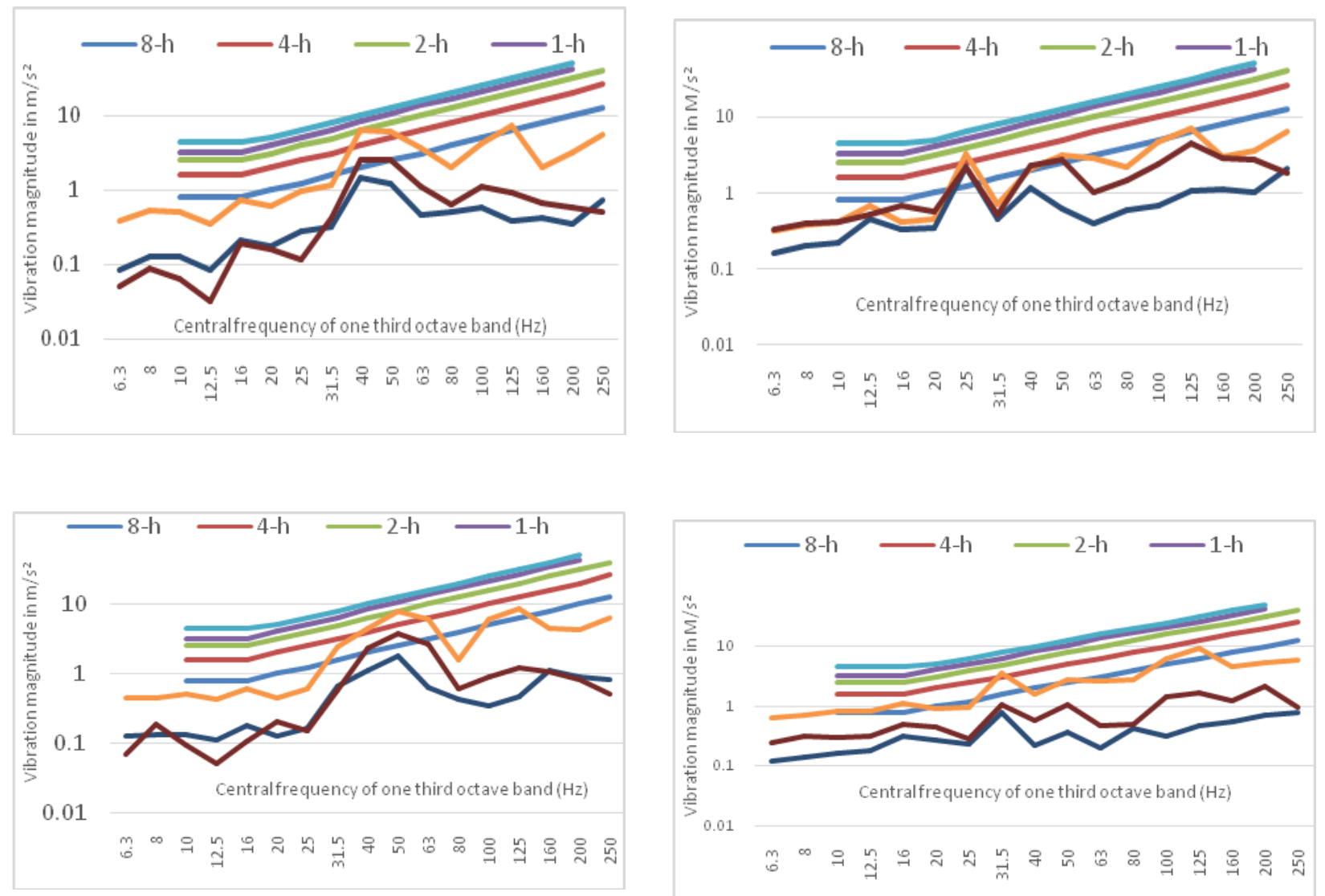

Frequency weighted vibrations for Rotary blade weeding at $1.2,1.5,1.8 \mathrm{kmph}$ with interventions
Frequency weighted vibrations for straight blade weeding at 1.2,1.5,1.8 kmph with interventions

Fig.5 Effect of the vibration intervention on straight and rotary blade

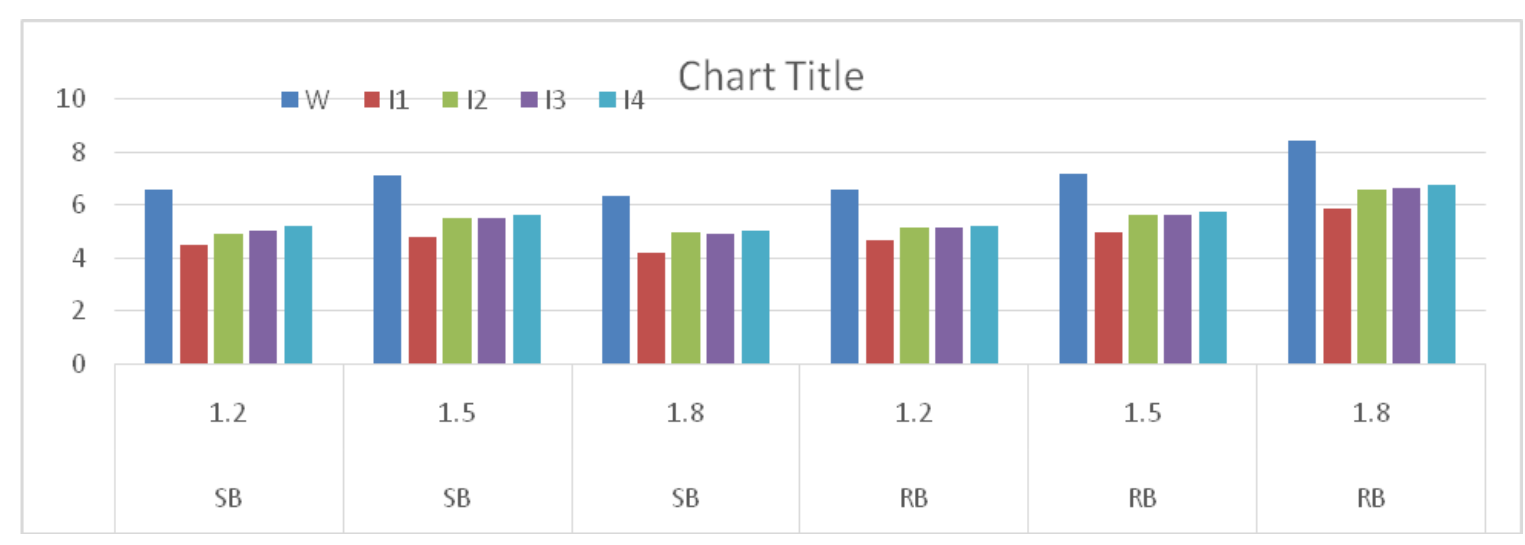

The magnitudes in $\mathrm{x}$ direction varied from 4.84 to $5.96 \mathrm{~m} / \mathrm{s}^{2}$ with the speed from 1.2 to
$1.8 \mathrm{kmph}$ with straight blade. In y direction the HTV were 2.72 and $2.86 \mathrm{~m} / \mathrm{s}^{2}$ higher than 
the other operation at 1.2 and $1.5 \mathrm{kmph}$. In $\mathrm{y}$ direction with straight blade vibration were at speed of 1.2 and $1.5 \mathrm{kmph}$ but at speed of $1.8 \mathrm{kmph}$ the vibration magnitude was 1.18 $\mathrm{m} / \mathrm{s}^{2}$ which is less than rotary weeder. The trend of vibration magnitude was similar in $\mathrm{z}$ direction as in case of y direction.

\section{Comparison of vibration magnitudes with ISO standards}

The one third octave band analysis was also done. Frequency spectra were obtained for all three axes for both operations. the vibration magnitudes were superimposed on ISO 5349 (1986) curves for different time durations of safe exposure.

In weeding with straight blade, the vibration magnitude increased with speed. The vibration magnitude in $\mathrm{x}$ direction was higher than $\mathrm{y}$ and $\mathrm{z}$ directions. The $\mathrm{x}$ axis acceleration exceeds $1 \mathrm{~h}, 1.5 \mathrm{~h}, 2 \mathrm{~h}$ exposure limit at 1.8, 1.5.1.2 kmph. The values for other two axis i.e. $\mathrm{Y}$ and $\mathrm{Z}$ were lower indicating higher duration of exposure limit. (Fig. 3-5).

One hour exposure limit was exceeded in $\mathrm{x}$ axis at both speeds 1.5 and $1.2 \mathrm{kmph}$. so with increase of the speed, the exposure limit was reduced from 2 hours to 1 hour. In operating condition one peak vibration was observed at $31.5 \mathrm{~Hz}$ during weeding with straight blade which may cause more harm to metacarpal. Dewangan and Tiwari (2008) reported that peak transmissibility at metacarpal was $31.5 \mathrm{~Hz}$ during rota puddling, which is also dominant frequency of vibrations of power tillers. Rota-tilling and weeding which was also the dominant frequency of vibration of hand tractor. They suggested that this may be because of resonance of the skin at metacarpal. The frequency at which resonance occurs have also been reported by different researcher. The resonance frequency of the hand reported were at 63 and resonance was reported at $50 \mathrm{~Hz}$ frequency in cutaneous, subcutaneous and muscle tissues of hand. In the present study another higher peak acceleration appears at $125 \mathrm{~Hz}$. but this may not have a detrimental effect as weighting has roll-off rate at higher frequencies (Mansfield. 2004)

In rotary weeder as the speed increase from 1.2 to $1.8 \mathrm{kmph}$ the daily vibration exposure limit exceeded the $0.5 \mathrm{~h}$ exposure limit in $\mathrm{x}$ direction (Fig. 3-5) The peak value in $x$ direction was found at $50 \mathrm{~Hz}$ and around 160 Hz. it is clear from the graphic representation that vibration levels were higher in $\mathrm{x}$ direction. The vibration magnitudes were concentration over a frequency range of 0-200 Hz. Ying et al., (1998) also reported the similar trend. They found that most vibration were concentrated in the frequency range of $0-20 \mathrm{~Hz}$ and the most serious vibration occurs in $\mathrm{x}$-direction.

\section{Vibration magnitude without intervention and with intervention}

The effect of interventions on HAV with different speeds and blades is given in table 1 and the mean values of HAV are given in table 1 .

It is observed that with intervention I1 i.e Synthetic rubber with soft foam rubber hand grip, there was reduction of 34 percent and 30.5 percent in HTV at speed of $1.8 \mathrm{kmph}$ for straight and rotary blade respectively followed by I2, I3, and I4 has the lesser reduction in the HTV but it has less HTV values than the control i.e No intervention.

It is observed that maximum time of exposure to vibrations was increased from one hour to two hours in case of rotary blade at all three speeds i. e 1.2,1.5,1.8kmph and the period was increased from two to four hours in case of straight blade weeding operations 
In conclusions the developed weeder was equipped with two types of blades i.e. straight blade and rotary blade. Hand arm vibration were taken for both blades using four different combination of rubber interventions and hand grips.

The Hand transmitted vibrations for all the tree axes as defined in ISO 5349(20010 was measured and recorded in different field operations. The maximum value vibration in $\mathrm{x}$ direction $5.96 \mathrm{~m} / \mathrm{s}^{2}$ and $8 \mathrm{~m} / \mathrm{s}^{2}$ in straight blade weeder, and rotary weeder respectively. The magnitudes were higher in $\mathrm{X}$ - direction indicating that $\mathrm{x}$-direction was major contributor in total vibration value. In rotary weeder magnitudes of vibration reduced in $\mathrm{Y}$ and $\mathrm{Z}$ direction at $1.8 \mathrm{kmph}$.

In weeding with straight blade, the vibration magnitude increased with speed. The vibration magnitude in $\mathrm{x}$ direction was higher than $\mathrm{y}$ and $\mathrm{z}$ directions. The $\mathrm{x}$ axis acceleration exceeds $1 \mathrm{~h}, 1.5 \mathrm{~h}, 2 \mathrm{~h}$ exposure limit at $1.8,1.5 .1 .2 \mathrm{kmph}$. The peak value in $\mathrm{x}$ direction was found at $50 \mathrm{~Hz}$ and around 160 Hz. it is clear from the graphic representation that vibration levels were higher in $\mathrm{x}$ direction. The vibration magnitudes were concentration over a frequency range of 0-20 $\mathrm{Hz}$.

With intervention I1 i.e Synthetic rubber with soft foam rubber hand grip, there was reduction of 34 percent and 30.5 percent in HTV at speed of $1.8 \mathrm{kmph}$ for straight and rotary blade respectively followed by I2,I3, and $\mathrm{I} 4$ has the lesser reduction in the HTV but it has less HTV values than the control i.e no intervention.

Maximum time of exposure to vibrations was increased from one hour to two hours in case of rotary blade at all three speeds i.e 1.2,1.5,1.8 $\mathrm{kmph}$ and the period was increased from two to four hours in case of straight blade weeding operations.

\section{References}

Anonymous (1990) ISO 2041: Vibration and Shock - Vocabulary. International Organization for Standardization, Geneva.

Anonymous (1992) IS 13548: Agricultural Wheeled Tractors and Field Machinery - Measurement of Whole-Body Vibration of the Operator. Pp 11. Bureau of Indian Standards, New Delhi, India

Anonymous (2001a) ISO 5349-1: Mechanical Vibration - Measurement and Evaluation of Human Exposure to Hand-Transmitted Vibration -Part 1: General Requirements. Pp 24. International Organization for Standardization, Geneva.

Anonymous (2001b) ISO 5349-2: Mechanical Vibration - Measurement and Evaluation of Human Exposure to Hand-Transmitted Vibration - Part 2: Practical Guidance for Measurement at the Workplace. Pp 39. International Organization for Standardization, Geneva.

Bhattacharya S K (1999) Assessment of noise and vibration with reference to health standard. Paper presented in a workshop on occupational health and safety in agriculture held at national institute of occupational health, Ahamedabad on Feb. 1418, pp 96-101

Bini Sam 2010 Effect of terrain conditions on vibration of power tillers International Journal of Agricultural Engineering, Vol. 3 No. 2 (October, 2010): 343 -347

Bini sam, K.Kathrivel 2009 Development and evaluation of Vibration isolators for reducing the hand transmitted vibrations of walking and riding type of powertiller Biosystems Engineering pp 
227to 237,2009

Gururaj T. Ramajjanavar (2015)

"Development and Evaluation of Anti-

Vibration Measures for Reducing Hand

Transmitted Vibration in Walking Type

Self Propelled Vertical Conveyor

Reaper" unpublished thesis in Farm

Machinery and Power Engineering to

MPAUT Udaipur
Varun Chaturvedi, Adarsh Kumar, I. M. Mishra, J. K. Singh, R. N. Sahoo, G. K. Jha and S. B. Lal Studys on interventions to reduce vibration transmission to power tiller operator Journal of Applied and Natural Science 8 (1): 265 - 272 (2016)

\section{How to cite this article:}

Munde, P. A., A. D. Harkal and Bhumare, G. S. 2020. Study of Hand Arm Vibration in VNMKV Developed Power Weeder. Int.J.Curr.Microbiol.App.Sci. 9(12): 1886-1894. doi: https://doi.org/10.20546/ijcmas.2020.912.224 